\title{
Cognitive Deterioration and Functional Compensation in ALS Measured with fMRI Using an Inhibitory Task
}

\author{
Kelsey Witiuk, ${ }^{1 *}$ (D) Juan Fernandez-Ruiz, ${ }^{2 \star}$ Ryan McKee, ${ }^{3}$ Nadia Alahyane, ${ }^{1}$ Brian C. Coe,,${ }^{1}$ Michel Melanson, ${ }^{3}$ \\ and Douglas P. Munoz ${ }^{1,3,4,5}$ \\ ${ }^{1}$ Centre for Neuroscience Studies, Queen's University, Kingston, Ontario K7L 3N6, Canada, ${ }^{2}$ Departamento de Fisiología, Facultad de Medicina, \\ Universidad Nacional Autónoma de México, Distrito Federal 04510, México, ${ }^{3}$ Department of Medicine, Division of Neurology, Queen’s University, \\ Kingston, Ontario K7L 3N6, Canada, ${ }^{4}$ Department of Biomedical and Molecular Sciences, Queen's University, Kingston, Ontario K7L 3N6, Canada, and \\ ${ }^{5}$ Department of Psychology, Queen's University, Kingston, Ontario K7L 3N6, Canada
}

Amyotrophic lateral sclerosis (ALS) is characterized by degeneration of upper and lower motor neurons, resulting in progressive weakness and muscle atrophy. Recent studies suggest that nondemented ALS patients can show selective cognitive impairments, predominantly executive dysfunction, but little is known about the neural basis of these impairments. Oculomotor studies in ALS have described deficits in antisaccade execution, which requires the implementation of a task set that includes inhibition of automatic responses followed by generation of a voluntary action. It has been suggested that the dorsolateral prefrontal cortex (DLPFC) contributes in this process. Thus, we investigated whether deterioration of executive functions in ALS patients, such as the ability to implement flexible behavior during the antisaccade task, is related to DLPFC dysfunction. While undergoing an fMRI scan, 12 ALS patients and 12 agematched controls performed an antisaccade task with concurrent eye tracking. We hypothesized that DLPFC deficits would appear during the antisaccade preparation stage, when the task set is being established. ALS patients made more antisaccade direction errors and showed significant reductions in DLPFC activation. In contrast, regions, such as supplementary eye fields and frontal eye fields, showed increased activation that was anticorrelated with the number of errors. The ALS group also showed reduced saccadic latencies that correlated with increased activation across the oculomotor saccade system. These findings suggest that ALS results in deficits in the inhibition of automatic responses that are related to impaired DLPFC activation. However, they also suggest that ALS patients undergo functional changes that partially compensate the neurological impairment.

Key words: amyotrophic lateral sclerosis; antisaccade; cognitive control; fMRI; prefrontal cortex; task set

\section{Introduction}

Amyotrophic lateral sclerosis (ALS) is a neurodegenerative disease affecting motor neurons in the cerebral cortex, brainstem, and spinal cord. The neuropathology of ALS is marked primarily by degeneration of upper motor neurons in the brainstem and motor cortex, and of lower motor neurons in the brainstem and spinal cord. The resulting muscle denervation leads to physical symptoms of muscle weakness, atrophy, and tone reduction, which progresses to the loss of voluntary movement (Kiernan et al., 2011).

Beyond motor impairments, patients with ALS often display behavioral and cognitive deficits, including dysfunctions within

Received March 10, 2014; revised Aug. 27, 2014; accepted Sept. 5, 2014.

Author contributions: R.M., B.C.C., N.A.,M.M., and D.P.M. designed research; K.W., J.F.-R., R.M., B.C.C., and M.M. performed research; K.W. and J.F.-R. analyzed data; K.W., J.F.-R., and D.P.M. wrote the paper.

This work was supported by ALS Society of Canada Bernice Ramsay Discovery Grant to D.P.M. and M.M. and Canadian Institutes of Health Research Operating Grant MOP-97741 to D.P.M. who was also supported by the Canada Research Chair Program. We thank members of the D.P.M. laboratory for comments on an earlier version of the manuscript.

The authors declare no competing financial interests.

*K.W. and J.F.-R. contributed equally to this work.

Correspondence should be addressed to Dr. Douglas P. Munoz, Centre for Neuroscience Studies, Queen's Univer-

sity, Kingston, Ontario K7L 3N6, Canada. E-mail: doug.munoz@queensu.ca.

DOI:10.1523/JNEUROSCI.1111-14.2014

Copyright $\odot 2014$ the authors $\quad 0270-6474 / 14 / 3414260-12 \$ 15.00 / 0$ the executive system (Gallassi et al., 1985; Strong et al., 1996; Abrahams et al., 2000; Phukan et al., 2007; Raaphorst et al., 2012). These deficits are commonly associated with pathologies in prefrontal circuits and can also be seen in patients with frontotemporal dementia (Abrahams et al., 1996; Murphy et al., 2007). Most brain imaging activation studies that investigated the neural basis of cognitive deficits in ALS have used tests that depend on verbal, written, or hand movement responses, which can be confounded by the ALS motor impairment. Nevertheless, these studies have found a general correlation between performance on different neuropsychological tests and reduced frontal lobe activity, including the dorsolateral prefrontal cortex (DLPFC) (Tsermentseli et al., 2012).

However, it is unknown how reduction in activity within a specific area would result in a specific executive dysfunction in ALS. A task that has been valuable to probe the processes involved in executive dysfunctions is the antisaccade task, which relies on the implementation of flexible behaviors (Hallett, 1978; Hallett and Adams, 1980). This flexibility has been attributed to variations in readiness to make a response or in the intention to perform a particular task and has been referred to as "preparatory set" (Everling and Munoz, 2000). Correct antisaccade execution requires a preparatory set that includes inhibition of automatic 


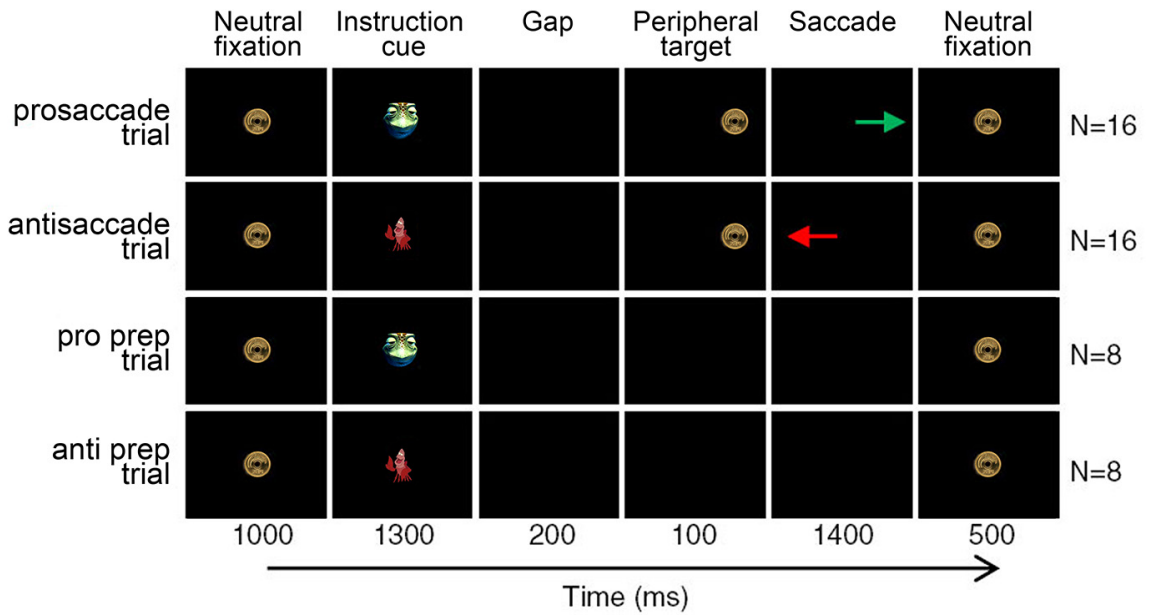

Figure 1. Behavioral paradigm. Representation of stimuli and timing of events for the four trial types. Trials were pseudorandomly presented and intermixed with periods of fixation on the neutral fixation stimulus that lasted $1.5,3$, and 4.5 s. Arrows indicate the correct saccade directions for the saccade trials and were not actually displayed. Fixation-only trials are not shown in this figure.

responses followed by the generation of a voluntary action toward the opposite site of the target (Guitton et al., 1985; Shaunak et al., 1995; Luna et al., 1998; Evdokimidis et al., 2002; Munoz and Everling, 2004). Functional imaging has helped identify the oculomotor network involved in the preparation and execution of antisaccades, including frontal cortex areas, such as the frontal eye fields (FEFs) and supplementary eye fields (SEFs), and the DLPFC (Luna et al., 1998; Munoz and Everling, 2004; Anderson et al., 2012; Jamadar et al., 2013).

The aim of this study was to test the hypothesis that deficits in the control of flexible behavior in ALS are related to deficient DLPFC activation, specifically during the antisaccade preparation stage. This hypothesis is supported by previous findings suggesting that the frontal lobe participates in the inhibition of unwanted automatic saccades (Guitton et al., 1985; PierrotDeseilligny et al., 2003). To examine this hypothesis, we measured the implementation of flexible behaviors using the antisaccade task in a group of ALS patients and age-matched controls during a rapid event-related fMRI acquisition.

\section{Materials and Methods}

All experiments were approved by the Research and Ethics Board of Queen's University and adhered to the principles of the Canadian TriCouncil Policy Statement on Ethical Conduct for Research Involving Humans, in accordance with the principles of the Declaration of Helsinki (World Medical Association, 2013). ALS patients and age-matched control subjects participated in a rapid event-related fMRI design with prosaccade and antisaccade trials interleaved with preparatory protrials and antitrials that did not include saccade executions ("catch" trials) (Fig. 1). This design allowed us to separately examine activation related to the preparation stage for an antisaccade, referred to as the task set, from activation related to executing the antisaccade response.

Participants. Twenty-one patients with definite ALS diagnoses and with no other neurological problem, including the presence of vascular lesions, agreed to participate in this study and were compensated for their time. They were recruited from the neuromuscular clinics at Saint Mary's of the Lake and Kingston General Hospitals by M.M. and were required to participate in two sessions held within $10 \mathrm{~d}$ apart. Nine of these patients were unable to complete the MRI studies primarily because of breathing difficulties while lying supine in the scanner. Twelve ALS patients (ages $44-76$ years, 2 females, mean \pm SD age $61.6 \pm 9.6$ years) completed all experimental procedures and were included in the final analysis (Table 1). It should be noted that one patient had an especially long disease duration (Patient 5 in Table 1). However, an extensive clinical analysis did not reveal any other neurological condition that could explain his symptoms. His initial presentation was an upper motor neuron type involving lower limbs. A control group of 12 healthy volunteers (ages 41-76 years, 3 females, mean \pm SD age $61.6 \pm 10.7$ years) were ageand gender-matched to the ALS patients and were included in the final analysis. Controls did not possess any neurological/psychiatric disorders as assessed by the experimenter and by scores on the Mini-Mental Status Examination (Folstein et al., 1983) or the Montreal Cognitive Assessment (MoCA) (Nasreddine et al., 2005).

Clinical evaluation of ALS patients was performed during the first session. This evaluation was modeled after a rapid screening battery used in ALS patients to measure physical function and frontal lobe impairments (FlahertyCraig et al., 2006). The measures of physical function included pulmonary function tests of forced vital capacity, the self-administered ALS Functional Rating Scale Revised version (Cedarbaum et al., 1999), manual strength tests of maximum voluntary isometric contraction of the dominant hand, and a patient history, including age and symptoms at disease onset, disease duration, and current medications being taken by the patient. Neuropsychological testing included the MoCA, the Frontal Behavioral Inventory (Kertesz et al., 1997), the Centre for Neurologic Study Lability Scale (Moore et al., 1997), a modification of the Hospital Anxiety and Depression Scale (Bjelland et al., 2002) to exclude one question which falsely exaggerated the measure of depression due to the physical disabilities experienced by ALS patients (Abrahams et al., 2000), the Neurobehavioral Cognitive Status Examination (Mueller et al., 2001) to assess verbal reasoning and judgment, and the Controlled Oral Word Association test (Benton, 1969) to assess verbal fluency, where the letters $\mathrm{C}, \mathrm{A}$, and $\mathrm{S}$ were used to avoid repetition from verbal fluency tasks in the MoCA. Verbal fluency represents the average time taken to think of each word (Abrahams et al., 2000) and is designed to control for individual variations in motor speed. Previously described normative data were used as a benchmark for age-matched control performance (Tombaugh et al., 1999).

fMRI experimental design. Brain imaging was acquired during the second session. A randomly interleaved, rapid event-related design was used (Cameron et al., 2012; Hakvoort Schwerdtfeger et al., 2012; Alahyane et al., 2014), allowing the presentation of different trial types within a reasonable time period. Included in the design were full prosaccade and antisaccade trials aimed at examining both the preparatory and execution components of saccades (Fig. 1, top 2 rows), preparatory-only trials (i.e., catch trials) that exclusively measured preparatory activation (Fig. 1, bottom 2 rows), and fixation-only trials (data not shown). Participants were asked to fixate on a neutral fixation stimulus (a "gold coin") that appeared for $1000 \mathrm{~ms}$ at the center of the screen to start each trial. The neutral fixation stimulus would change to an instructional cue indicating to the participant that a prosaccade or an antisaccade was required. The symbols used for the instructional cue were colored diagram images: a green turtle indicated that a prosaccade was required, and a red crab indicated that an antisaccade was required. Colored diagram symbols were chosen because the rapid event-related experiment was designed for use across various patient groups that included child-aged participants, and this made the task easier for children to learn.

After the $1300 \mathrm{~ms}$ presentation of the instructional cue, a $200 \mathrm{~ms}$ gap period occurred during which the participant was presented with a black screen. The gap period was introduced to enable participants to generate more "automatic" saccades and has been associated with shorter saccadic reaction times (SRTs), more antisaccade direction errors, and more express prosaccades (Munoz and Corneil, 1995; Fischer and Weber, 1997; Munoz et al., 1998). On saccade trials, a peripheral target (gold coin) was 
Table 1. Clinical and neuropsychological information for ALS patients included in the imaging study ${ }^{a}$

\begin{tabular}{|c|c|c|c|c|c|c|c|c|c|c|c|c|c|c|c|c|c|}
\hline \multirow[b]{3}{*}{ Patient no. } & \multirow{3}{*}{$\begin{array}{l}\text { Months since } \\
\text { diagnosis }\end{array}$} & \multicolumn{8}{|c|}{ Clinical evaluation } & \multicolumn{8}{|c|}{ Neuropsychological evaluation } \\
\hline & & \multirow{2}{*}{$\begin{array}{l}\text { El Escorial } \\
\text { criteria }\end{array}$} & \multirow[b]{2}{*}{ Onset } & \multirow{2}{*}{$\begin{array}{l}\text { FVC } \% \\
\text { pred }\end{array}$} & \multirow{2}{*}{$\begin{array}{l}\text { ALS } \\
\text { FRS-R }\end{array}$} & \multirow{2}{*}{$\begin{array}{l}\text { MVIC } \\
(\mathrm{kg})\end{array}$} & \multirow{2}{*}{$\begin{array}{l}\text { ULT } \\
\text { (/70) }\end{array}$} & \multirow{2}{*}{$\begin{array}{l}\text { LLT } \\
(/ 70) \\
\end{array}$} & \multirow[b]{2}{*}{ Hand } & \multirow{2}{*}{$\begin{array}{l}\text { MoCA } \\
(/ 30)\end{array}$} & \multicolumn{2}{|c|}{ Cognistat } & \multirow{2}{*}{$\begin{array}{l}\text { COWA } \\
\text { (VF) }\end{array}$} & \multirow[b]{2}{*}{$\mathrm{FBI}$} & \multirow[b]{2}{*}{ CNS-LS } & \multicolumn{2}{|c|}{ HADS } \\
\hline & & & & & & & & & & & $\mathrm{R}$ & J & & & & D & $A$ \\
\hline 2 & 20 & def & LL & 90 & 41 & 45 & 70 & 42 & L & 25 & 8 & 6 & 4.70 & 2 & 7 & 1 & 0 \\
\hline 3 & 84 & def & $\mathrm{LL}$ & 92 & 29 & & 38 & 70 & L & 24 & 4 & 5 & 7.00 & 24 & 11 & 9 & 9 \\
\hline 4 & 12 & def & UL & 101 & 41 & 31 & 64 & 62 & L & 21 & 4 & 4 & 12.10 & 12 & 11 & 3 & 2 \\
\hline 7 & 13 & def & UL & 62 & 28 & 3 & 50 & 60 & R & 29 & 8 & 6 & 2.93 & 10 & 15 & 5 & 5 \\
\hline 8 & 22 & def & LL & 78 & 36 & 18 & 70 & 43 & $\mathrm{R}$ & 25 & 8 & 6 & 4.14 & 13 & 11 & 3 & 2 \\
\hline 9 & 18 & def & LL & 88 & 42 & 30 & 69 & 60 & $\mathrm{R}$ & 18 & 7 & 5 & 3.50 & 5 & 9 & 3 & 9 \\
\hline 10 & 16 & def & UL & 74 & 43 & 3 & 53 & 68 & L & 29 & 7 & 6 & 4.88 & 3 & 7 & 1 & 1 \\
\hline 11 & 10 & def & LL & 77 & 31 & 50 & 64 & 26 & $\mathrm{R}$ & 23 & 8 & 5 & 9.11 & 4 & 9 & 3 & 7 \\
\hline 12 & 11 & def & Bulbar & 94 & 33 & 3.3 & 56 & 65 & $\mathrm{R}$ & 26 & 8 & 5 & 3.83 & 4 & 13 & 4 & 1 \\
\hline
\end{tabular}

${ }^{a}$ ALSFRS-R, ALS Functional Rating Scale Revised version; CNS-LS, Centre for Neurologic Studies Lability Scale; Cognistat R/J, Verbal Reasoning and Judgment questions from Neurobehavioral Cognitive Status Examination; COWA, Controlled Oral Word Association test; def, definite diagnosis; FBI, Frontal Behavioral Inventory; FVC \% pred, forced vital capacity percent predicted when sitting; HADS D/A, Depression and Anxiety measures of Hospital Anxiety and Depression Scale; Hand, dominant hand as identified by Modified Edinburgh Handedness Inventory; LLT, lower limb total of Manual Muscle test; MoCA, Montreal Cognitive Assessment; MVIC, maximum voluntary isometric contraction; ULT, upper limb total of Manual Muscle test.

flashed for $100 \mathrm{~ms}$ to the left or right of the neutral fixation, at eccentricities of either $6^{\circ}$ or $7^{\circ}$ in separate trials, to signal a saccade. Participants had $1400 \mathrm{~ms}$ to execute the appropriate prosaccade (look toward the target location) or antisaccade (look away from the target in the opposite direction) based on the instructional cue presented in that trial. The neutral fixation stimulus (gold coin) then reappeared at the center of the screen for $500 \mathrm{~ms}$, and participants were required to reestablish central fixation to initiate the next trial. Before commencing the task, participants were instructed to make a correction saccade if they generated direction errors. On catch trials, the instructional cue was presented and disappeared to initiate the gap period, but the peripheral target did not appear to signal a saccade; subjects were instead required to maintain central fixation for the remainder of the trial $(1700 \mathrm{~ms})$ without generating a saccade. Participants did not know whether or not the peripheral target would appear on any given trial; thus, the instruction cue would always elicit preparation for a prosaccade or antisaccade. Full saccade, catch, and fixation only trials were $4500 \mathrm{~ms}$ in duration. The duration of the intertrial interval was jittered, using fixation periods that spanned 1 repetition time (TR) (1.5 s; 8 times), 2 TR ( $3.0 \mathrm{~s} ; 4$ times), and 3 TR (4.5 $\mathrm{s} ; 4$ times) to increase the statistical efficiency and power in the rapid event-related design (Dale, 1999).

Runs consisted of 64 trials that included 8 procatch trials, 8 anticatch trials, 16 prosaccade trials, 16 antisaccade trials, and 16 fixation trials (Fig. 1; fixation trials not shown). Trial types were pseudo-randomly interleaved, and right and left prosaccade and antisaccade trials were presented in equal quantities within each run. Each participant performed 5-9 runs (depending on eye tracking success), with each run lasting $277.5 \mathrm{~s}$. Each run started with an additional fixation period of $3 \mathrm{~s}$, whereas fMR images were acquired, to allow the MR signal to reach a steady state. Each run ended with a $16.5 \mathrm{~s}$ fixation period to allow the hemodynamic response to return to baseline before commencing the next run. Each subject was given a practice run before entering the magnet.

Visual display and eye tracking. Visual stimuli were generated and controlled using E-PRIME software (Psychology Software Tools) on a personal computer. Images were back-projected onto a high-contrast rear projection screen (DA-LITE), positioned at the head end of the magnet bore, using a NEC LT265 DLP video projector with a refresh rate of $60 \mathrm{~Hz}$ and a resolution of $1024 \times 768$. Participants viewed the screen via a mirror attached to the head coil (described below). Eye position data were recorded using an ISCAN ETL-400 camera that sampled the eye position at a frequency of $120 \mathrm{~Hz}$. To ensure synchronization, the MRI sequences directly triggered the E-PRIME software using a trigger signal from the scanner. An infrared fiber-optic illuminator, which was fixed to the head coil, was used to illuminate the right eye for tracking. After the anatomical MRI scan was acquired, the eye tracker was calibrated using a nine-point array that covered most of the visual field. Analysis of the eye movement data was performed off-line using custom-made MATLAB programs (MathWorks).

Imaging protocol. All imaging data were acquired at the Queen's University MRI Facility using a Siemens 3 Tesla Magnetom Trio system fitted with a 12-channel receive-only head coil. High-resolution T1-weighted whole-brain structural scans were performed on each participant using an MPRAGE sequence $\left(\mathrm{TR}=1760 \mathrm{~ms}, \mathrm{TE}=2.2 \mathrm{~ms}\right.$, flip angle $=9^{\circ}$, $256 \times 256 \mathrm{~mm}$ field of view, and $256 \times 256$ matrix size providing $1 \mathrm{~mm}$ isotropic voxels, 176 slices). Functional data were collected using a T2*weighted EPI acquisition $\left(\mathrm{TR}=1500 \mathrm{~ms}, \mathrm{TE}=30 \mathrm{~ms}\right.$, flip angle $=72^{\circ}$, $211 \times 211 \mathrm{~mm}$ field-of-view, $64 \times 64$ matrix size, $3.3 \mathrm{~mm}$ isotropic voxel resolution, 185 volumes) for BOLD-based imaging (Ogawa et al., 1990). Twenty-four slices were acquired and positioned to include all regions of interest extending from the top of the brain to the ventral striatum (STR).

MRI preprocessing. All functional imaging runs were preprocessed using Brain Voyager 1.9. The first two volumes of each functional run were discarded before any preprocessing, to allow for steady-state magnetization. To correct for between-scan movements, all volumes within a run were realigned to the first volume of that functional run. Slice scan time correction was conducted to adjust for time differences due to multislice imaging acquisition using a cubic spline interpolation, which was based on the TR duration and order of slice scanning (ascending interleaved). 3D spatial smoothing was then performed using a $4 \mathrm{~mm}$ full-width at half-maximum Gaussian filter on all volumes, and each run was filtered to remove linear drift using a high-pass filter with the upper cutoff frequency corresponding to 3 cycles over the length of the run. Finally, all functional data were superimposed onto $3 \mathrm{D}$ anatomical images, resampled into $3 \mathrm{~mm}$ cubic voxels, aligned to the anterior commissureposterior commissure axis, and transformed into Talairach space (Talairach and Tournoux, 1988).

Behavioral analyses. Behavioral data were analyzed using customwritten scripts in MATLAB 7.4 (MathWorks). SRT was defined as the time to make the first saccade away from fixation after peripheral stimulus onset. Saccades with a SRT $<90$ ms were considered anticipatory (Munoz et al., 1998) and thus were excluded from analysis. This value was selected because it was the point at which errors in prosaccade trials were no longer executed at chance (1:1 ratio correct: incorrect). Therefore, $90 \mathrm{~ms}$ was decided as the earliest time at which detection of the visual target could influence behavior. Express saccades, which are the shortest visually triggered saccades, have typically been calculated as saccades with SRTs between 90 and 135 ms (Fischer et al., 1993; Munoz et 
al., 1998); however, the boundaries of this epoch change according to the participant age and stimulus conditions (Bell et al., 2006; Peltsch et al., 2011; Marino et al., 2012). In the current study, the express saccade epoch was measured between 90 and $160 \mathrm{~ms}$, where $160 \mathrm{~ms}$ was the latency at which both groups made more correct responses than errors during antisaccade trials (data not shown). Prosaccade direction errors were defined as saccades executed away from the target during prosaccade trials; antisaccade direction errors were defined as saccades executed toward the target during antisaccade trials. Direction error rate was calculated by dividing the total number of errors by the total number of valid trials. Intrasubject variability for SRT was calculated using the coefficient of variation for correct trials $(\mathrm{SD} /$ mean $\times 100)$.

Valid trials consisted of all trials except for those that included the following: (1) failure to fixate during fixation trials; (2) failure to fixate during the instruction period of a full prosaccade or antisaccade trial; (3) failure to execute a saccade during the response period; (4) execution of multiple saccades during the response period; (5) saccades executed during catch trials; (6) antisaccades executed during prosaccade trials; (7) failure to correct an antisaccade direction error; and (8) trials in which eye-tracking was unsuccessful. These aforementioned excluded trials were modeled separately as "invalid trials" in the fMRI analysis described below.

Mixed-design ANOVAs were conducted to examine differences in behavior between the control and ALS groups in terms of SRT, CVSRT, percentage of express saccades, and percentage of direction errors during antsaccade- and prosaccade trials. Nonparametric two-sample Kolmogorov-Smirnov tests were conducted to compare the SRT cumulative distributions between the two groups. Group differences on saccade measures were not observed between leftward versus rightward saccades or between $6^{\circ}$ versus $7^{\circ}$ eccentricities $(p>0.05)$; therefore, these responses were pooled. Furthermore, $2 \times 2$ repeated-measures ANOVAs were used to measure between-group differences of saccade metrics, including prosaccade and antisaccade duration, amplitude, and velocity. The variables were group with two levels (ALS, controls) and task with two levels (pro, anti).

fMRI main contrast analyses. The BOLD time series for each voxel was deconvolved with the canonical hemodynamic response function to estimate the underlying time course of neural activity. The hemodynamic response function was modeled as a 13-point time series with a temporal resolution of $1.54 \mathrm{~s}$. Events were modeled separately in the design matrix according to trial type, including the following: (1) anticatch trials, (2) procatch trials, (3) correct antisaccade trials, (4) correct prosaccade trials, (5) corrected antisaccade direction errors, and (6) invalid trials. Fixation trials were used as an implicit baseline.

Several statistical parametric maps were computed for each group, reflecting the statistical significance of the response consistency for each voxel within each trial type, as defined above. To identify the saccaderelated neural network, we looked at correct full antisaccade trials and full prosaccade trials over BOLD time points 5-7 (7.7, 9.3, and $10.8 \mathrm{~s}$ from trial onset), which corresponded to the time intervals of the peak of the BOLD responses from the instructional cue presentation to the execution of the saccade. These analyses resulted in group-level statistical maps that were generated at a false discovery rate corrected threshold of $p<0.01$ (T value $=5.0$ ). To identify the most reliable responses, using the cluster threshold estimator plugin for BrainVoyager QX, we also calculated the minimum cluster size necessary to achieve a false activation probability $\alpha=0.05$ (Forman et al., 1995). This procedure excluded clusters $<49$ contiguous voxels. These statistical maps constitute the main contrast, and were used for subsequent ROI second-level analyses pertaining to task set establishment and response execution.

fMRI ROI analyses. ROIs were chosen based on previous functional imaging studies that showed consistent activation in these areas during prosaccade and antisaccade execution and preparation (Luna et al., 1998; DeSouza et al., 2003; Connolly et al., 2005; Ford et al., 2005; Brown et al., 2006, 2007; Raemaekers et al., 2007; Cameron et al., 2012; Hakvoort Schwerdtfeger et al., 2012; Jamadar et al., 2013). The following ROIs were selected from the main contrast to perform second level analyses and are known to participate in the saccade network: the frontal pole (FP), DLPFC, the insula, the anterior cingulate cortex (ACC), the STR, the
SEFs, the FEF, the precuneus (PCu), and the parietal eye fields (PEFs). ROI analyses were conducted using random-effects Gaussian linear models to extract $\beta$-weight parameter estimates of BOLD signal change during saccades from each ROI. ROIs were identified using anatomical landmarks and known locations in Talairach space. Each ROI was defined as the 125 contiguous voxels $(5 \times 5 \times 5)$ within a cubic cluster centered on the point of peak activation within the selected region. Peak preparatory activation was measured as the mean $\beta$-weight values from the fifth and sixth time points following catch trial onset. For analysis of the saccade execution processes, the time points were shifted by $1.5 \mathrm{~s}$ to include the sixth and seventh time points following saccade trial onset, as the presentation of the peripheral target occurs $1.5 \mathrm{~s}$ (one time point) after the appearance of the instruction (Brown et al., 2007; Alahyane et al., 2014). Mixed-design Split-Plot ANOVAs with one within-subjects factor (with two levels: pro and anti) and one between-subjects factor (with two levels: control group and ALS group) were then conducted to examine differences in mean $\beta$-weight values for all ROIs. Paired Student's $t$ tests were conducted to analyze the preparatory differences between correct and error trials within the ALS group using the $\beta$-weight averages of the fifth and sixth time points. Finally, to evaluate the relationship between BOLD signal change and task performance, Pearson's correlations were performed between $\beta$-weight values and behavioral measurements, including SRT, CV, and proportion of direction errors.

\section{Results}

\section{Clinical and neuropsychological evaluation}

Scores from the clinical and neuropsychological evaluations of ALS patients are summarized in Table 1. All patients included in the study met the El Escorial criteria for "definite" ALS diagnosis. Five patients had upper limb onset, six had lower limb onset, and only one had bulbar onset. The mean disease duration for all patients at the time of the clinical evaluation was 37.3 months (range, 10-168 months), and the mean vital capacity was $83.1 \%$ predicted (forced vital capacity range, $62-101$ ). The mean \pm SD ALS Functional Rating Scale Revised version evaluation of physical disability was $36.3 \pm 5.6$.

The neuropsychological tests revealed considerable deficits in the ALS patients. The mean MoCA score was $24.8 \pm 3.5$ of 30 points, which is above the average mild cognitive impairment average of 22 points (Nasreddine et al., 2005). The ALS patients performance on each MoCA domain was as follows: visuospatial/ executive $4.33 \pm 0.77$ (of 5), naming $2.91 \pm 0.28$ (of 3), attention (sum) $5.16 \pm 1$ (of 6), language (sum) $2.41 \pm 0.9$ (of 3), abstraction $1.75 \pm 0.45$ (of 2), delayed recall $3 \pm 1.47$ (of 5), and orientation $5.91 \pm 0.28$ (of 6).The Neurobehavioral Cognitive Status Examination reasoning and judgment scores $(6.8 \pm 1.7$ and $5.3 \pm$ 0.7 , respectively) fell within the average ranges reported for healthy adults (Kiernan et al., 2011). The mean verbal fluency score was $6.1 \pm 3.9$ (range 2.9-14.8), which is within the lower range of previous reports (Massman et al., 1996; Abrahams et al., 2000; Ahn et al., 2011).

The ALS patients Frontal Behavioral Inventory score ranged from 2 to 42 , with an average of $11.0 \pm 11.7$. One patient had a score of $\geq 27$, which is required for a diagnosis of frontal lobe dementia (Kertesz et al., 1997). Mean Centre for Neurologic Study Lability Scale emotional lability score was $10.8 \pm 3.6$. A score of $\geq 13$ suggests emotional lability (Moore et al., 1997). ALS participants did not display signs of depression or anxiety in the Hospital Anxiety and Depression Scale test. All but one patient fell within the normal range for anxiety. The average depression score of $2.9 \pm 2.4$ and anxiety score of $4.3 \pm 3.1$ fell within the normal range of $0-7$ points (Zigmond and Snaith, 1983). 
A
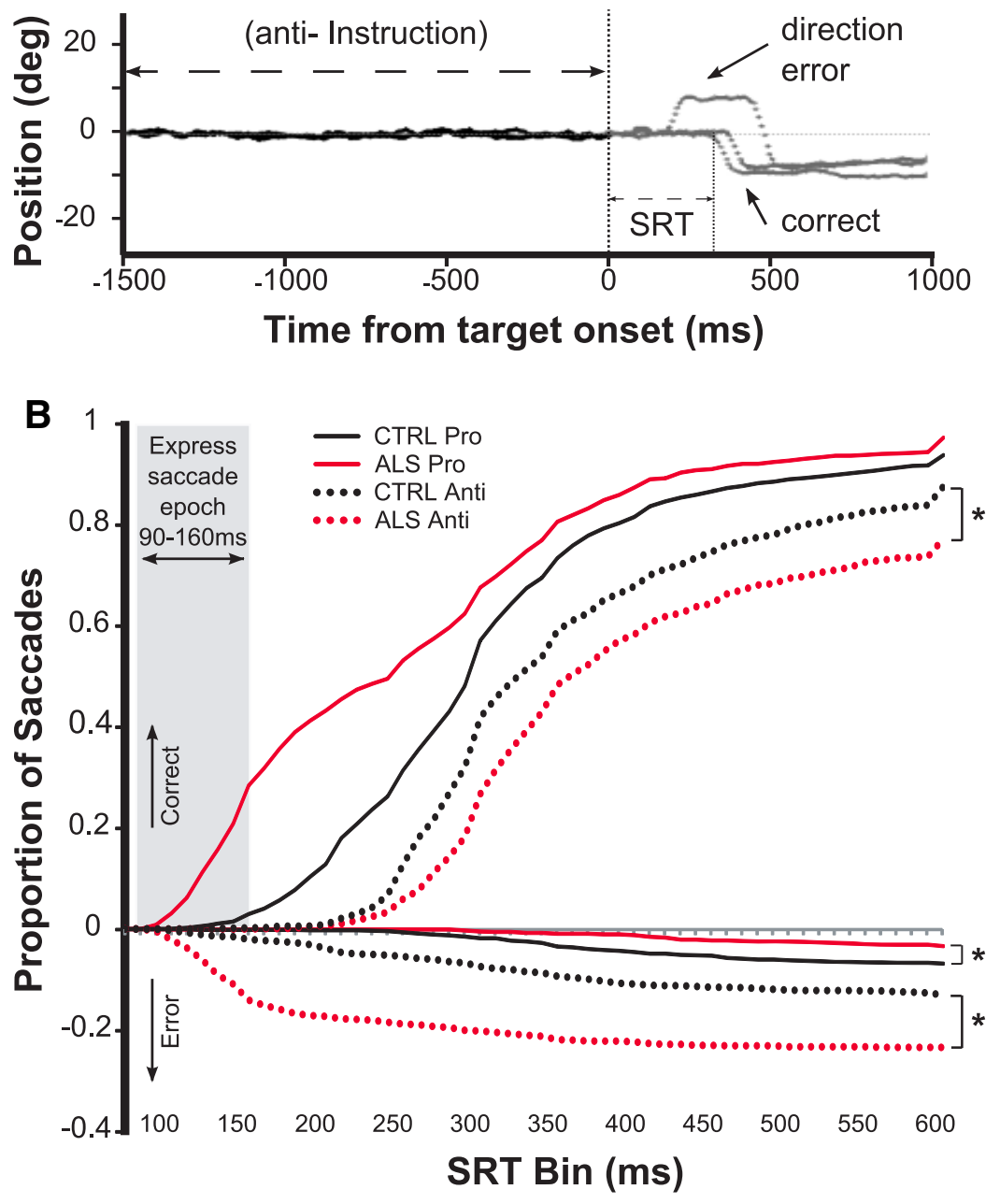

C
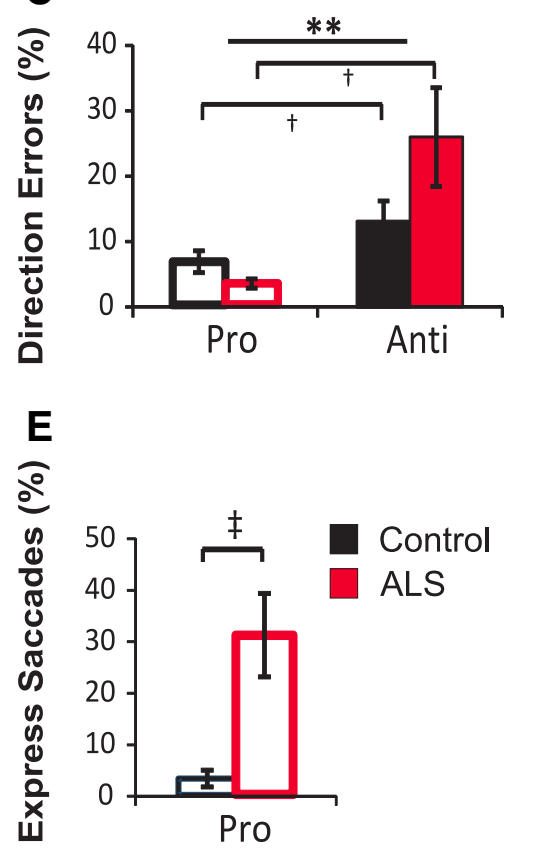

D
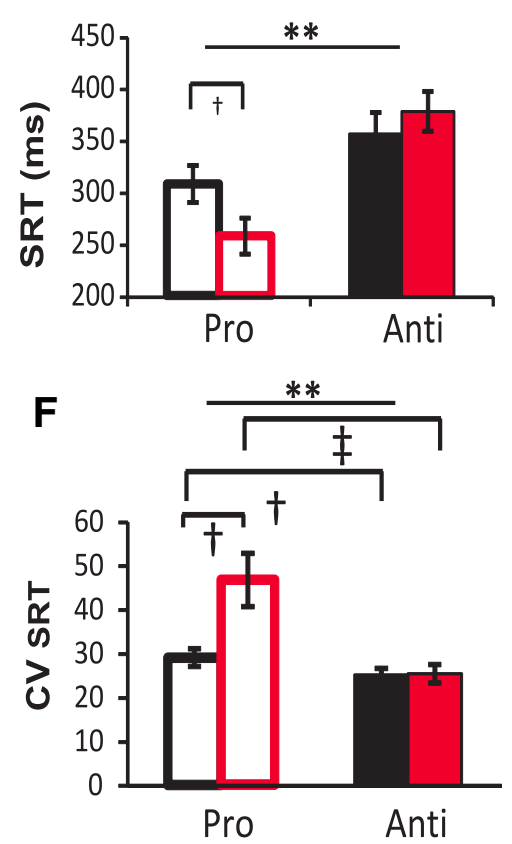

Figure 2. Eye movement behavioral data. $\boldsymbol{A}$, Sample eye traces depicting correct antisaccade trials and an erroneous antisac cade trial (direction error) followed by a correction. $\boldsymbol{B}$, Cumulative probabilities of saccade distributions for the two groups (pooled SRT across subjects). Positive $Y$ values indicate correct saccades, whereas negative $Y$ values indicate direction errors; dashed lines

Eye movement behaviors

Eye movement behavioral data are shown in Figure 2. Sample control eye traces depicting correct antisaccade trials and an erroneous antisaccade trial (direction error) followed by a correction are shown in Figure $2 A$.

\section{SRT cumulative distribution}

The cumulative distribution of SRTs for the prosaccade and antisaccade tasks are displayed as a proportion of the total number of trials, where the latencies of correct and incorrect saccades were categorized into SRT bins of $10 \mathrm{~ms}$ increments (Fig. $2 B$ ). In the prosaccade task, ALS subjects were much faster than controls and many responses fell within the express saccade epoch (Fig. 2B, gray bar). In contrast, on the antisaccade task, control subjects were faster at responding than ALS patients. Cumulative SRT distributions using the nonparametric two-sample Kolmogorov-Smirnov test were significantly different across ALS and control groups for correct antisaccades $(\mathrm{K}=$ 1.435, $p<0.033)$, incorrect antisaccade trials $(\mathrm{K}=4.489, p<0.001)$, and incorrect prosaccade trials $(K=2.490, p<$ $0.001)$. Distributions of correct prosaccade SRTs between ALS and controls were not significantly different when all SRT bins were included $(\mathrm{K}=1.272, p<$ 0.079); however, SRT distributions in the express saccade epoch only (90-160 ms) were significantly different between groups $(\mathrm{K}=1.500, p<0.022)$ (Fig. $2 B)$.

\section{Saccade direction errors}

The ALS group made significantly more direction errors on the antisaccade task than in the prosaccade task $\left(t_{(11)}=-2.61\right.$, $p=0.02$ ) (Fig. $2 C$ ), whereas the control group direction errors on the antisaccade task showed a large trend toward significance $\left(t_{(11)}=-2.12, p=0.057\right)$ compared with the prosaccade task. The analysis of group by condition interaction

$\leftarrow$

indicate antitrials; solid lines indicate protrials; black lines indicate control; red lines indicate ALS patients. Gray shaded region represents the region categorized as "express saccades" $(90 \leq \mathrm{SRT} \leq 160 \mathrm{~ms})$. Asterisks indicate significant shifts in error rates between the control group and the ALS group. $C$, Mean percentage direction errors (initial saccade away from target on prosaccade trial, toward target on antisaccade trial). $\boldsymbol{D}$, Mean SRTs on correct trials. $\boldsymbol{E}$, Mean percentage of express saccades ( $90-160 \mathrm{~ms}$ ). $\boldsymbol{F}$, Mean intrasubject CVSRT. Error bars indicate SEM. $\dagger p<0.05$, significance for group $\times$ task interactions only. $\neq p<0.01$, significance for group $\times$ task interactions only. ${ }^{*} p<0.05 .{ }^{* *} p<0.01$, significance for main effects of task. 


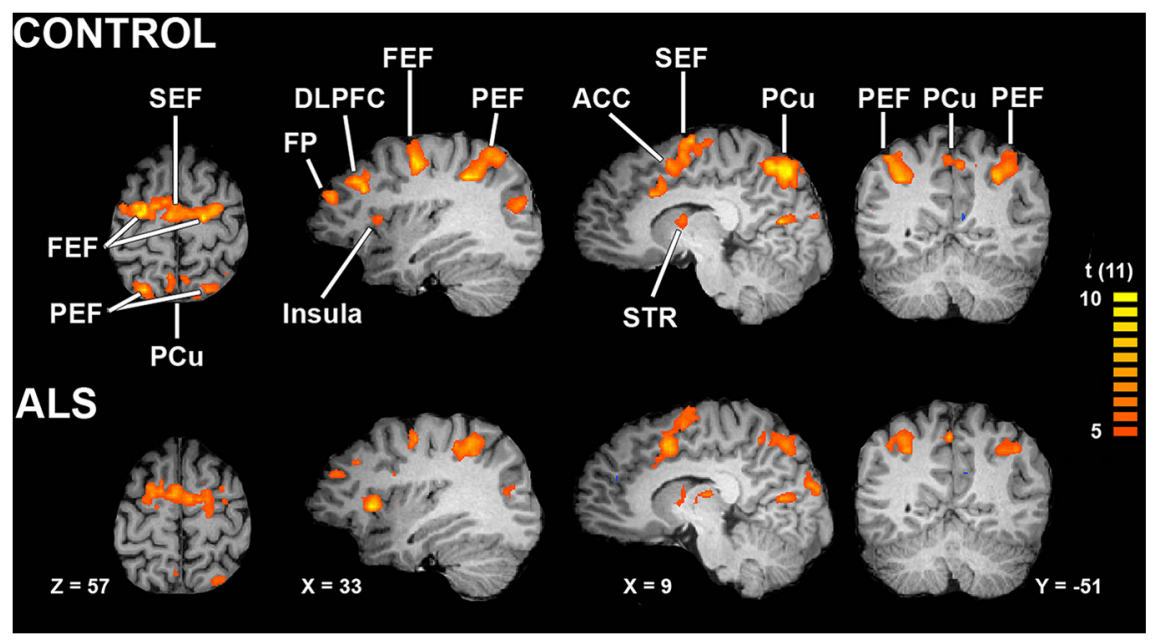

Figure 3. Saccade network. Contrast map of combined correct prosaccade trials and antisaccade trials corrected using false discovery rate at $p<0.01$ ( $t$ value $=5.0, \mathrm{df}=11$ ). The identified ROIs were cluster-corrected across the population of voxels with $p<0.05$ (49 contiguous voxels, as estimated by Brain Voyager's (luster-level Statistical Threshold Estimator with 1000 iterations).

of express saccades on prosaccade trials compared with controls $\left(t_{(22)}=-2.37\right.$, $p=0.027, \mathrm{~d}=-1.3)$ (Fig. 2E).

\section{SRT variability}

SRT intrasubject variability was expressed as a CV (Fig. 2F). A main effect of task was found for CVSRT $\left(F_{(1,22)}=17.57, p<\right.$ $\left.0.01, \eta_{p}^{2}=0.444\right)$ such that prosaccade SRTs were significantly more variable within subjects than antisaccades. A significant group effect was also observed $\left(F_{(1,22)}=6.85, p=0.016, \eta_{p}^{2}=0.237\right)$, where ALS patients had more variability for CVSRT than controls. The interaction between group and task also reached significance $\left(F_{(1,22)}=9.7, p<0.01, \eta_{p}^{2}=\right.$ $0.306)$, likely as a result of the increased prosaccade variability in the ALS group.

\section{Saccade metrics}

An ANOVA revealed no significant main

Table 2. Regions of interest ${ }^{a}$

\begin{tabular}{|c|c|c|c|c|c|c|c|c|c|}
\hline \multirow[b]{2}{*}{ ROI } & \multirow[b]{2}{*}{$\mathrm{CH}$} & \multicolumn{3}{|c|}{ Control } & \multirow[b]{2}{*}{ T value } & \multicolumn{3}{|l|}{ ALS } & \multirow[b]{2}{*}{ T value } \\
\hline & & $X$ & Y & $Z$ & & $X$ & $Y$ & $Z$ & \\
\hline \multirow[t]{2}{*}{$\mathrm{FP}$} & $\mathrm{L}$ & -35 & 43 & 19 & 4.18 & -35 & 41 & 19 & 5.55 \\
\hline & $\mathrm{R}$ & 28 & 44 & 22 & 7.93 & 35 & 41 & 26 & 7.78 \\
\hline \multirow[t]{2}{*}{ DLPFC } & $\mathrm{L}$ & -40 & 26 & 32 & 4.14 & -39 & 31 & 33 & 5.99 \\
\hline & $\mathrm{R}$ & 36 & 27 & 31 & 9.54 & 36 & 31 & 33 & 7.28 \\
\hline \multirow[t]{2}{*}{ Insula } & $L$ & -29 & 26 & 7 & 8.76 & -28 & 20 & 6 & 10 \\
\hline & $\mathrm{R}$ & 30 & 21 & 9 & 9.56 & 31 & 18 & 7 & 10.11 \\
\hline \multirow[t]{2}{*}{$A C C$} & $\mathrm{~L}$ & - & - & - & - & - & - & - & - \\
\hline & $\mathrm{R}$ & 8 & 3 & 45 & 7.59 & 9 & 8 & 44 & 9.61 \\
\hline \multirow[t]{2}{*}{ STR } & $\mathrm{L}$ & -21 & -3 & 7 & 8.44 & -27 & -1 & 8 & 9.48 \\
\hline & $\mathrm{R}$ & 21 & -7 & 10 & 9.47 & 24 & 1 & 7 & 7.5 \\
\hline \multirow[t]{2}{*}{ SEF } & $\mathrm{L}$ & -6 & -11 & 56 & 8.28 & -6 & -3 & 54 & 9.65 \\
\hline & $\mathrm{R}$ & 3 & -11 & 57 & 10.03 & 3 & -1 & 57 & 8.82 \\
\hline \multirow[t]{2}{*}{ FEF } & $\mathrm{L}$ & -20 & -13 & 57 & 10.79 & -19 & -7 & 62 & 12.81 \\
\hline & $\mathrm{R}$ & 23 & -5 & 54 & 16.18 & 24 & -6 & 52 & 8.56 \\
\hline \multirow[t]{2}{*}{$\mathrm{PCu}$} & $\mathrm{L}$ & -24 & -66 & 48 & 10.59 & -26 & -57 & 46 & 6.81 \\
\hline & $\mathrm{R}$ & 27 & -62 & 42 & 17.03 & 27 & -58 & 45 & 6.78 \\
\hline \multirow[t]{2}{*}{ PEF } & $\mathrm{L}$ & -24 & -66 & 48 & 13.42 & -26 & -57 & 46 & 6.81 \\
\hline & $\mathrm{R}$ & 27 & -62 & 42 & 15.78 & 27 & -58 & 45 & 7.28 \\
\hline
\end{tabular}

${ }^{a}$ Talairach coordinates $(X, Y, Z)$ of cubic clusters containing the 125 most significant voxels centered around peak activation in GLM contrast maps for antisaccade + prosaccade contrast (Fig. 3). All ROls were 125 voxels taken at local maxima. CH, Cerebral hemisphere.

also resulted in a trend between group and task $\left(F_{(1,22)}=3.21\right.$, $\left.p=0.08, \eta_{p}^{2}=0.127\right)$. Analysis of the direction errors revealed no main effect of group $\left(F_{(1,22)}=0.842, p=0.37, \eta_{p}^{2}=0.037\right)$. However, there was a significant main effect of task $\left(F_{(1,22)}=\right.$ $\left.10.01, p<0.01, \eta_{p}^{2}=0.313\right)$.

\section{Saccadic reaction times}

Analysis of SRTs (Fig. 2D) showed a significant main effect of task $\left(F_{(1,22)}=27.76, p<0.01, \eta_{p}^{2}=0.558\right)$, with significantly prolonged antisaccade latencies as previously reported (Shaunak et al., 1995; Donaghy et al., 2010). However, there was no main effect of group $\left(F_{(1,22)}=0.617, p=0.44, \eta_{p}^{2}=0.027\right)$, or group $\times$ task interactions $\left(F_{(1,22)}=3.94, p=0.06, \eta_{p}^{2}=0.152\right)$.

\section{Express saccades}

The express saccade epoch was defined within the 90-160 ms interval. The ALS group made a significantly greater proportion effect of group on saccade amplitude $\left(F_{(1,22)}=0.66, p=0.42\right.$, $\left.\eta_{p}^{2}=0.029\right)$ or saccade velocity $\left(F_{(1,22)}=1.24, p=0.27, \eta_{p}^{2}=\right.$ $0.053)$, suggesting that ALS patients did not have significantly altered saccade metrics. A main effect of task was observed for saccade amplitude $\left(F_{(1,22)}=7.96, p=0.01, \eta_{p}^{2}=0.266\right)$, where antisaccades had significantly greater amplitudes than prosaccades. A significant interaction effect between group and task on saccade amplitude $\left(F_{(1,22)}=9.37, p<0.01, \eta_{p}^{2}=0.299\right)$ was followed by pairwise comparisons, which revealed that antisaccades had significantly greater amplitudes than prosaccades only within the ALS group $(p=0.003)$. Saccade velocity showed no main effect of task $\left(F_{(1,22)}=1.3, p=0.265, \eta_{p}^{2}=0.056\right)$ but displayed a significant interaction between group and task $\left(F_{(1,22)}\right.$ $\left.=7.92, p=0.01, \eta_{p}^{2}=0.265\right)$.

\section{Behavioral correlations}

Prosaccade and antisaccade SRTs and direction errors were correlated with neuropsychological test scores from Table 1. All correlations of antisaccade SRTs were found to be not significant ( $p$ values $>0.11)$. All correlations of antisaccade direction errors were also found to be not significant ( $p$ values $>0.062$ ), with the exception of the MoCA score where a two-tailed Pearson's correlation revealed a significant negative correlation between the ALS group's performance on the MoCA and the percentage of antisaccade errors made $\left(\mathrm{r}_{(12)}=-0.686, p<0.01\right)$, where antisaccade error rates increased as MoCA scores worsened.

\section{fMRI results}

The saccade network

An initial analysis was performed to identify regions involved in the preparation and execution of prosaccade and antisaccades. This global analysis identified an oculomotor network that is consistent with previous reports using fMRI to delineate saccaderelated areas (Luna et al., 1998; Connolly et al., 2002; Ford et al., 2005; Brown et al., 2006, 2007; Anderson et al., 2012; Jamadar et al., 2013). Our results included FP, DLPFC, insula, SEF, FEF, STR, PCu, and PEF. Figure 3 depicts the most relevant slices for this network for the control and ALS groups, and Table 2 lists the Talairach locations of peak activation for all key ROIs. Both groups recruited all predefined ROIs, suggesting that the observed behavioral deficits in the ALS group likely were attributed 


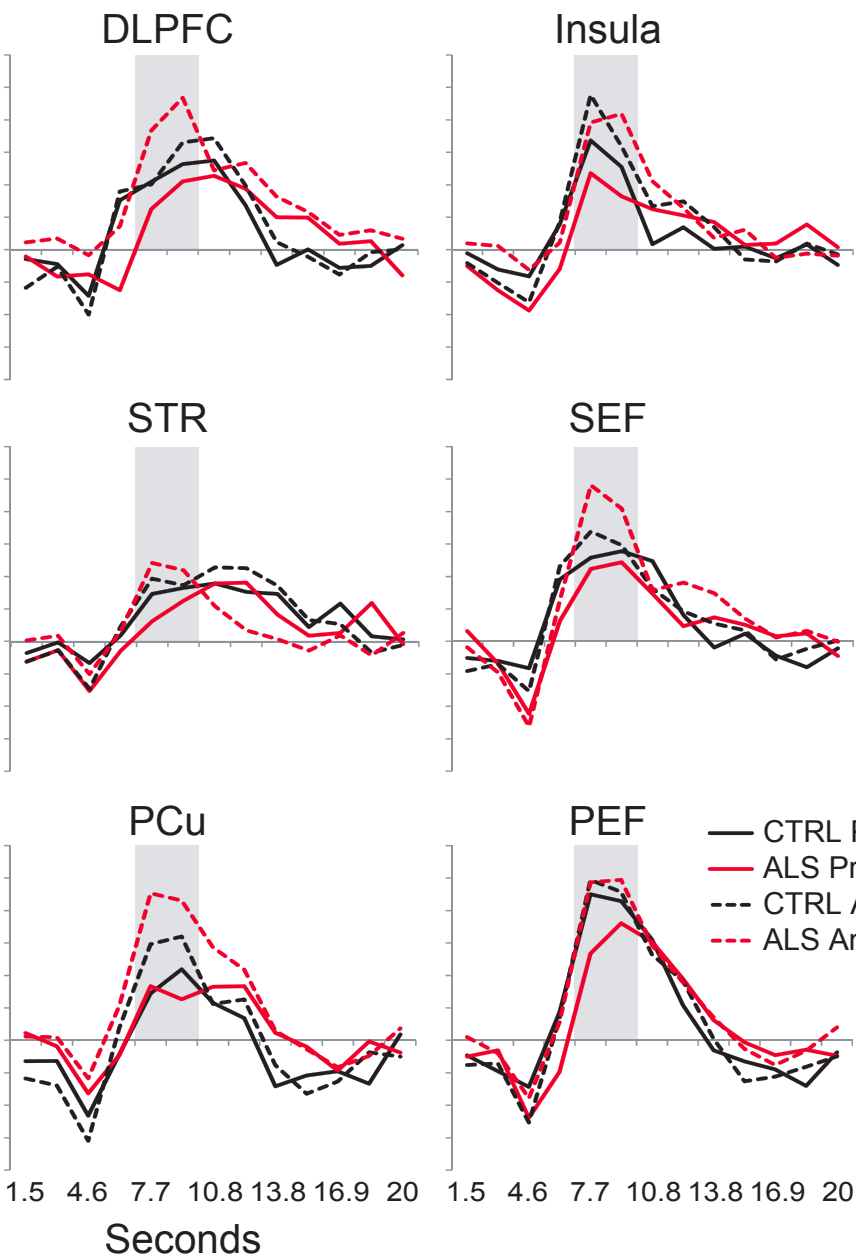
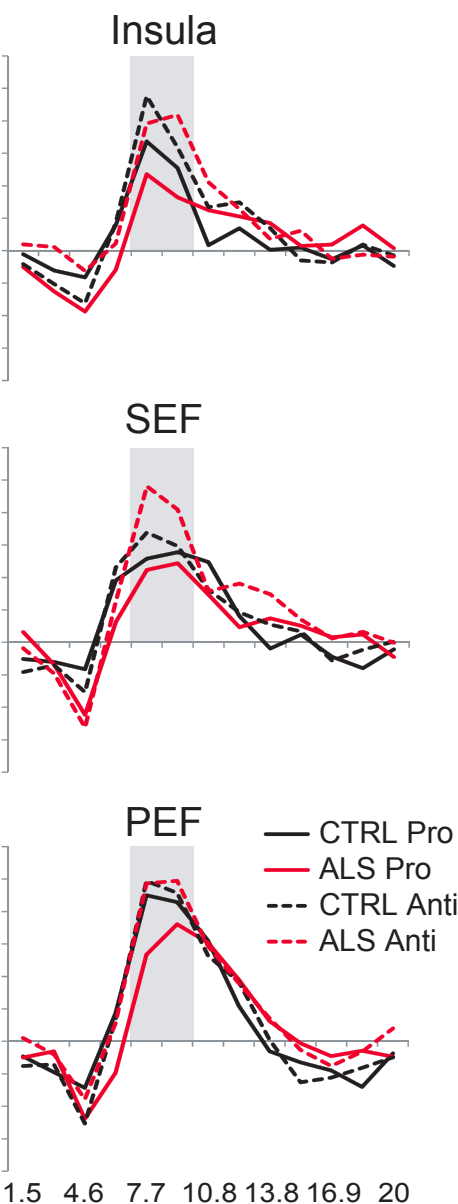

Figure 4. ROl activation time course. Average activity time courses in the preparatory network ROIs during pro (solid lines) and anti (dashed lines) for control (black) and ALS patients (red). Gray bar represents the time points used for subsequent analysis.

to critical differences in subprocesses of prosaccade and antisaccade control (i.e., saccade preparation or execution). The ROIs obtained from this analysis were then selected for second-level analyses to dissect the differential contribution of the preparatory and execution processes.

\section{The preparatory network}

Once the saccade network ROIs were defined, the BOLD signal time courses corresponding to the catch trials were obtained (Fig. 4). To dissect the effect of ALS pathology on the processes specifically involved in the preparation of the oculomotor network to an impending prosaccade or antisaccade, we analyzed the fifth and sixth time points (7.7 and $9.3 \mathrm{~s}$ from trial onset) of the procatch and anticatch trials (Fig. 5). Group comparisons of the average of these time points obtained from the local maxima $\beta$ weight values at all ROIs are shown in Figure 5. We were especially interested in analyzing whether ALS patients responded differently from controls when they had to inhibit the automatic response in contrast to simply produce the automatic response (i.e., we were interested in the interaction between these two conditions). Prosaccade and antisaccade catch trials were evaluated to determine which oculomotor regions were recruited by the ALS group compared with controls when preparing a saccade response to the prosaccade or antisaccade visual cue. The group (control and ALS) by condition (prosaccade and antisaccade) interaction was significant for all ROIs with the exception of the ACC (Fig. 5). A significantly greater preparatory response was evoked on antisaccade catch trials by the ALS group in the following regions: $\operatorname{FP}\left(F_{(1,46)}=4.27, p=0.04, \eta_{p}^{2}=0.089\right)$, DLPFC $\left(F_{(1,46)}=16.14, p<0.01, \eta_{p}^{2}=0.241\right)$, insula $\left(F_{(1,46)}=11.10, p<\right.$ $\left.0.01, \eta_{p}^{2}=0.202\right)$, ACC $\left(F_{(1,23)}=16.14, p<0.01, \eta_{p}^{2}=0.241\right)$, $\operatorname{STR}\left(F_{(1,46)}=5.22, p=0.02, \eta_{p}^{2}=0.106\right), \operatorname{SEF}\left(F_{(1,46)}=8.00, p<\right.$ $0.01, \eta_{p}^{2}=0.154, \operatorname{FEF}\left(F_{(1,46)}=13.96, p<0.01, \eta_{p}^{2}=0.241\right), \mathrm{PCu}$ $\left(F_{(1,46)}=11.67, p<0.01, \eta_{p}^{2}=0.210\right)$, and $\operatorname{PEF}\left(F_{(1,46)}=4.94\right.$, $p=0.03, \eta_{p}^{2}=0.101$ ). The analysis of the condition (prosaccade vs antisaccade) yielded significant differences in all areas: FP $\left(F_{(1,44)}=15.41, p<0.01, \eta_{p}^{2}=0.25\right), \operatorname{DLPFC}\left(F_{(1,44)}=25.94, p<\right.$ $\left.0.01, \eta_{p}^{2}=0.37\right)$, insula $\left(F_{(1,44)}=8.32, p<0.01, \eta_{p}^{2}=0.15\right)$, ACC $\left(F_{(1,44)}=16.06, p<0.01, \eta_{p}^{2}=0.42\right)$, STR $\left(F_{(1,44)}=11.84, p<\right.$ $\left.0.01, \eta_{p}^{2}=0.21\right), \operatorname{SEF}\left(F_{(1,44)}=20.9, p<0.01, \eta_{p}^{2}=0.32\right), \mathrm{PCu}$ $\left(F_{(1,44)}=6.37, p=0.01, \eta_{p}^{2}=0.12\right), \operatorname{PEF}\left(F_{(1,44)}=11.34, p<\right.$ $0.01, \eta_{p}^{2}=0.20$.

To analyze the effect of the heightened antisaccade preparatory activation in the ALS group on saccade behavior, we correlated the mean $\beta$ weights from anticatch trials to the antisaccade reaction times for each ALS patient (Fig. 6). Significant negative correlations were found between antisaccade reaction times and mean $\beta$ weights in all preparatory oculomotor ROIs, with the exception of the ACC, PCu, and PEF, suggesting that subjects 

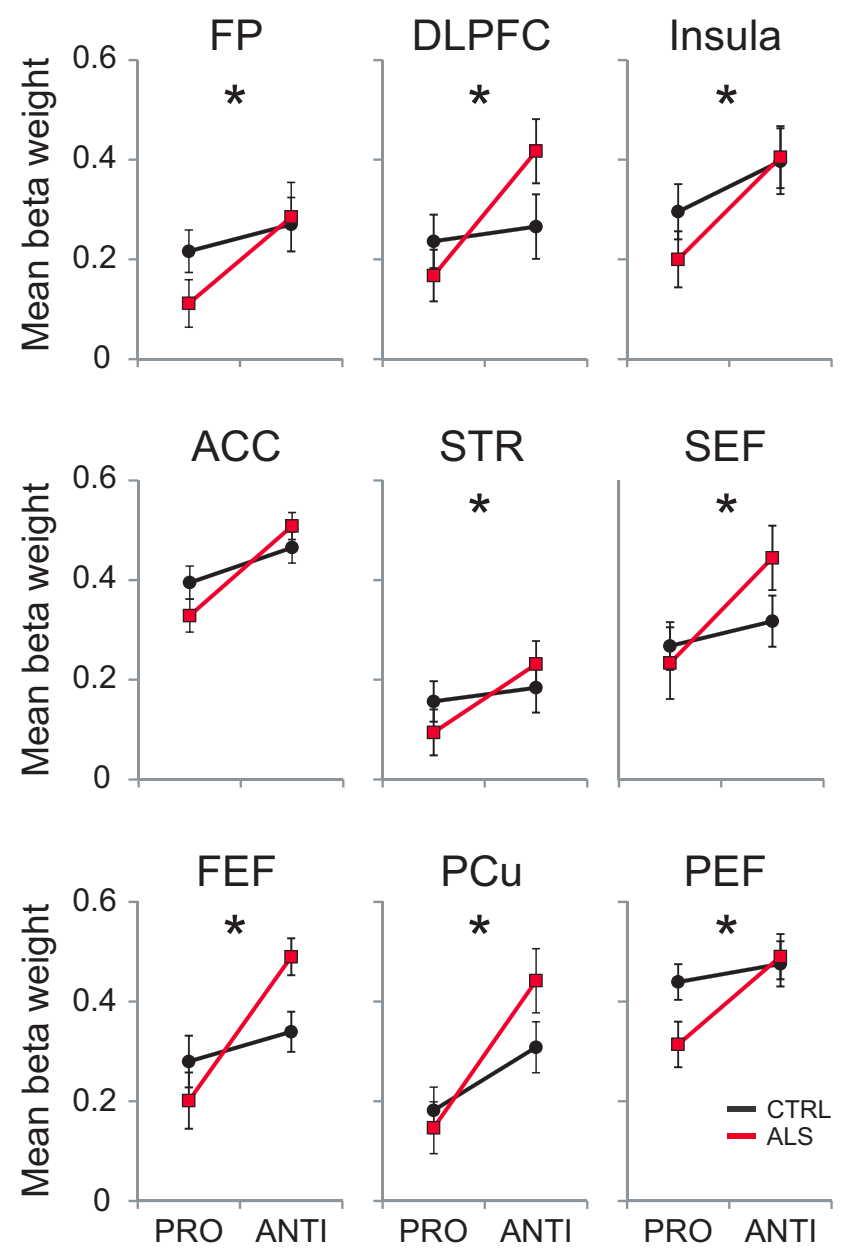

Figure 5. Rol procatch and anticatch trials analysis. Group $\times$ condition interaction analysis using the mean $\beta$ weight peak activity during procatch and anticatch trials for control and ALS groups. Note the heightened activity increase in the anticatch condition in all areas in the ALS group. ACC also showed a significant activity increase in the anticatch condition; however, the group $\times$ condition interaction did not reach significant levels. Error bars indicate $S E .{ }^{*} p<$ 0.05 .

who showed heightened activation when preparing to make an antisaccade were able to execute faster antisaccade reaction times (Fig. 6).

The saccade execution network

To isolate ROI activation involved in the execution of a prosaccade or antisaccade, we analyzed the mean peak $\beta$ weights of each region using the sixth and seventh time points (9.3 and $10.8 \mathrm{~s}$ from trial onset) of prosaccade and antisaccade trials minus the preparatory activation from catch trials reported above. The group $\times$ condition interaction analysis was significant in the insula $\left(F_{(1,44)}=4.84, p=0.03, \eta_{p}^{2}=0.09\right)$, and showed a trend in $\operatorname{PEF}\left(F_{(1,44)}=3.09, p=0.08, \eta_{p}^{2}=0.06\right)$. The analysis of the condition (prosaccade vs antisaccade) yielded significant differences in the $\operatorname{ACC}\left(F_{(1,44)}=5.65, p=0.027, \eta_{p}^{2}=0.20\right)$, STR $\left(F_{(1,44)}=10.15, p<0.01, \eta_{p}^{2}=0.18\right), \operatorname{SEF}\left(F_{(1,44)}=10.92, p<\right.$ $\left.0.01, \eta_{p}^{2}=0.19\right), \mathrm{PCu}\left(F_{(1,44)}=21.58, p<0.01, \eta_{p}^{2}=0.32\right), \mathrm{PEF}$ $\left(F_{(1,44)}=20.39, p<0.01, \eta_{p}^{2}=0.31\right)$, but not in FP, DLPFC, insula, or FEF. Finally, the analysis of the group effect resulted in a significant decrease only in $\operatorname{PEF}\left(F_{(1,44)}=5.09, p=0.02, \eta_{p}^{2}=\right.$ $0.10)$. These results show little disruption to the saccade execution network, suggesting that the main detrimental ALS effect is associated with saccade preparation.

\section{Direction errors}

To analyze the underlying deficits in saccade preparation that correlated with antisaccade errors in the ALS group, we analyzed the fifth and sixth time points of the antisaccade error trials and compared them with their respective time points obtained from correct antisaccade trials for each ROI. ALS patients showed a significant decrease in DLPFC activation $\left(t_{(23)}=2.45, p=0.02\right)$, an increase in insula activation $\left(t_{(23)}=-2.16, p=0.041\right)$, and an increase trend in SEF $\left(t_{(23)}=-1.92, p=0.06\right.$ ) (Fig. 7, left column) on antisaccade error trials compared with correct trials. There were no significant differences between correct and error antisaccade trials in the other areas: $\mathrm{FP}\left(t_{(23)}=1.53, p=\right.$ not significant $), \operatorname{ACC}\left(t_{(23)}=-.03, p=\right.$ not significant $), \operatorname{STR}\left(t_{(23)}=\right.$ 1.73, $p=$ not significant $), \operatorname{FEF}\left(t_{(23)}=-1.45, p=\right.$ not significant $), \mathrm{PCu}\left(t_{(23)}=.09, p=\right.$ not significant $)$, and $\operatorname{PEF}\left(t_{(23)}=\right.$ $-1.24, p=$ not significant). A similar analysis in the control subjects showed significant decreases in activation on error trials only in $\operatorname{FEF}\left(t_{(23)}=2.3, p=0.03\right)$, and $\operatorname{PEF}\left(t_{(23)}=2.8\right.$, $p=0.01)$.

To investigate the effect of antisaccade preparation on saccade behavior, we correlated the preparatory BOLD signal of each subject with the individual direction error performance during the antisaccade task in all ROIs of the saccade network. The analyses resulted in two significant negative correlations: one in SEF $(r=-0.66, p=0.03)$ and the other in FEF $(r=-0.77, p<0.01)$ ( $r=-0.66, p=$ not significant) (Fig. 7 , right column). The correlation analyses in all the other regions were not significant: FP $(r=0.28, p=$ not significant $), \operatorname{DLPFC}(r=-0.13, p=$ not significant), insula $(r=-0.56, p=$ not significant $)$, ACC $(r=$ $-0.48, p=$ not significant), STR $(r=0.48, p=$ not significant $)$, $\mathrm{PCu}(r=-0.35, p=$ not significant $)$, and PEF $(r=-0.40, p=$ not significant).

\section{Discussion}

We tested whether deterioration in the implementation of flexible behaviors in ALS is directly associated with DLPFC dysfunction. To this end, we used a prosaccade and antisaccade task coupled with $\mathrm{fMRI}$ and eye tracking. We found that ALS patients were significantly impaired when implementing flexible behavior, as demonstrated by a greater proportion of antisaccade direction errors (Fig. $2 B, C$ ). This error-related impairment was accompanied by a significant reduction in DLPFC activity (Fig. 7). A bias toward automatic responses in ALS was also demonstrated by a greater proportion of express saccades and more variable prosaccade SRTs (Fig. $2 E, F$ ). The results also showed functional changes that included significant increased activation in critical areas of the antisaccade network, such as FEF, SEF, and DLPFC, during saccade preparation. ALS patients showing these heightened responses during this task set establishment period also showed better performance during the antisaccade task (Fig. 6).

\section{Behavioral deficits in ALS}

Our results confirmed that ALS patients had antisaccade impairments (Shaunak et al., 1995; Evdokimidis et al., 2002; Donaghy et al., 2010) joining a body of research that has confirmed that ALS patients show oculomotor deficits in addition to the evident motor deterioration related to the motor neuron degeneration (Jacobs et al., 1981; Leveille et al., 1982; Ohki et al., 1994; Shaunak et al., 1995; Donaghy et al., 2010; Sharma et al., 2011; Burrell et al., 2013). The oculomotor deficits documented in ALS include ophthalmoplegia (Harvey et al., 1979), defective pursuit (Jacobs et al., 
1981), saccadic impairments (Shaunak et al., 1995; Donaghy et al., 2010), nystagmus (Kushner et al., 1984), and abnormal Bell phenomenon (Esteban et al., 1978). Defects in pursuit have been attributed to nonnuclear involvement of extrapyramidal or corticobulbar components of the oculomotor system. Saccadic impairments reported include slowing of vertical saccades, increased incidence of errors, and increased latency on the antisaccade task. Surprisingly, reflexive saccades appear to remain relatively intact, with bulbar onset demonstrating somewhat slower reflexive saccades than limb onset patients (Donaghy et al., 2010).

The significant increase of express saccades in ALS patients is a novel finding. Express saccades are elicited when high levels of pretarget activity combine with visual responses in saccade-related neurons of the superior colliculus (Dorris et al., 1997; Dorris and Munoz, 1998; Everling et al., 1998, 1999). During the gap period, pretarget preparatory activity is elevated and conditions are optimal for express saccade generation, making suppression of an unwanted saccade on an antisaccade trial very difficult, unless sufficient inhibition from the frontal lobes is exerted on saccade neurons in superior colliculus (Everling et al., 1998, 1999; Munoz and Everling, 2004). ALS patients show defective intracortical inhibition, leading to deficits in inhibitory interneuronal circuits that result in hyperexcitable cortical neurons (Ziemann et al., 1997). Therefore, the ALS patients' bias toward automatic express saccades could be the result of high levels of motor preparation activity because of defective intracortical inhibition, combined with poor executive control resulting from DLPFC impairment.

We also investigated whether there was any correlation between the eye movement behaviors and the neuropsychological tests. The only significant finding was that the ALS antisaccade error rate was inversely correlated with the MoCA score, which places more emphasis on frontal executive and attentional process than the more traditional Mini-Mental Status Examination (Smith et al., 2007). However, we did not find correlations with other general measurements of frontal lobe function, such as Frontal Behavioral Inventory or Controlled Oral Word Association. Previous findings show a large variation in this regard. Some studies have reported a lack of correlations between clinical data and oculomotor measurements (Shaunak et al., 1995), whereas others have shown significant correlations with frontal lobe dependent tasks, such as the Wisconsin Card Sorting Test (Evdokimidis et al., 2002) or the Stroop task (Donaghy et al., 2010). However, in the last study, the correlations with the Stroop measures were only found in bulbar onset patients. It also should be noted that ALS patients' cognitive performance varied considerably (Table 1), suggesting a continuum of impairments in this group of patients.

\section{Saccade network activity}

To perform a successful antisaccade, several cortical and subcortical brain regions must be recruited, including DLPFC (Guitton et al., 1985; Pierrot-Deseilligny et al., 2003), FEF, PEF, and SEF (Connolly et al., 2002; Curtis and D'Esposito, 2003; DeSouza et al., 2003; Ford et al., 2005; Brown et al., 2007), and basal ganglia (Cameron et al., 2009; Ford and Everling, 2009; Watanabe and Munoz, 2010, 2011, 2013). It is well documented that preparatory neural activity established before the appearance of the peripheral target presets the motor system to execute the appropriate action (Everling and Munoz, 2000; Curtis and D'Esposito, 2003; DeSouza et al., 2003). Here we showed that ALS patients recruited a similar neural network during both the preparatory and the execution stages of prosaccades and antisaccades. However, the results from our study revealed critical differences in activation not only between ALS and control group, but also within correct and incorrect antisaccade trials of ALS patients, which can help explain the observed oculomotor deficits in this group of ALS patients.

The analysis of the preparatory activity during prosaccades and antisaccades yielded significant between-group differences for the entire preparatory saccade network. These differences were driven by a significant increase of preparatory activity in response to the antisaccade cue compared with the prosaccade cue in the ALS group. Previous ALS imaging studies using block 

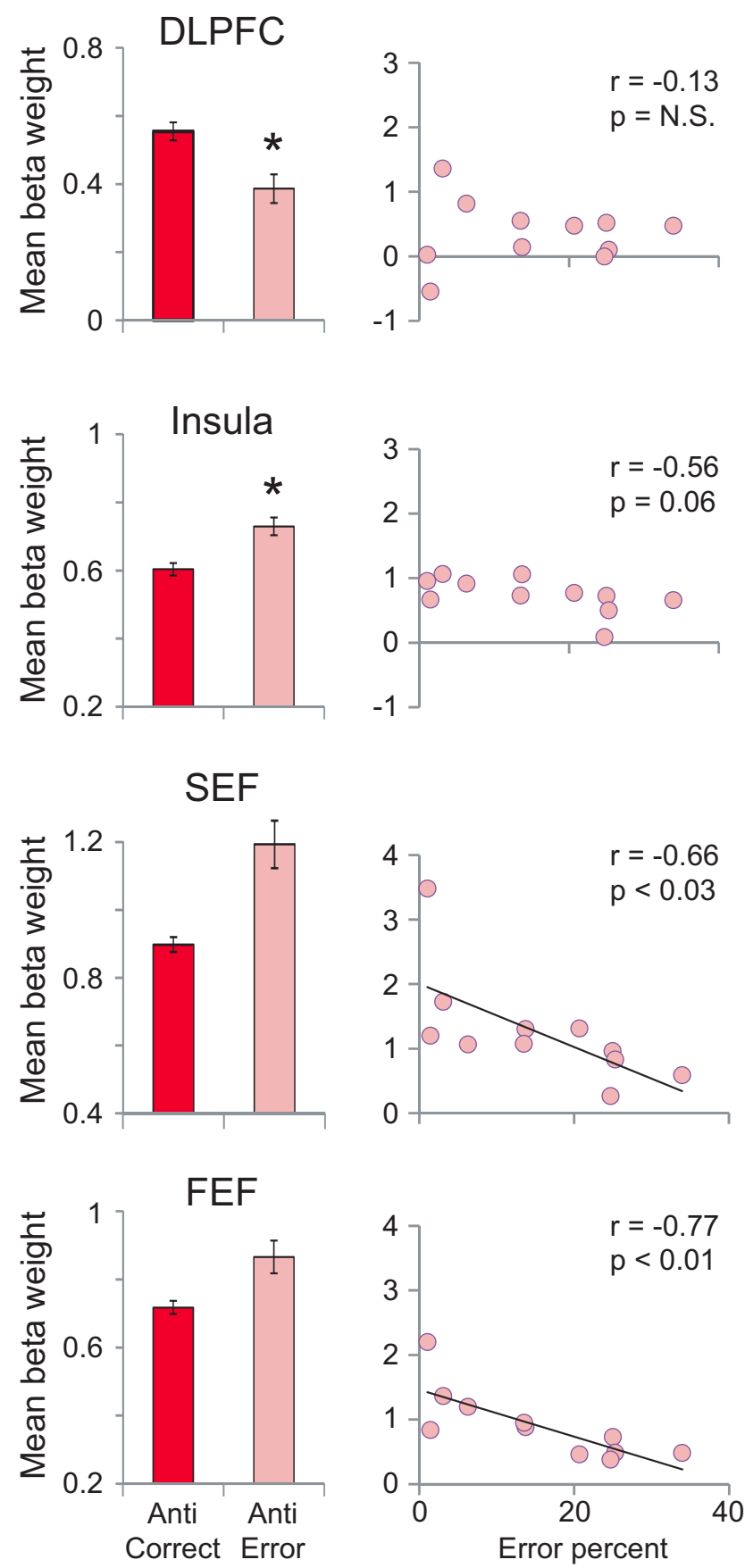

Figure 7. Direction errors analysis. Left, Mean $\beta$ weight peak activity during correct and error trials in the antisaccade task for the ALS group. Note the significant reduced activity in DLPFC during error trials. Right, Correlations between mean $\beta$ weight peak activities during antisaccade error trials with the percentage of errors. Note how the increased activity in the insula, SEF, and FEF correlated with fewer errors. Error bars indicate SE. ${ }^{*} p<0.05$.

designs have found significant increases of activity during various tasks in patients (Mohammadi et al., 2011; Cosottini et al., 2012; Poujois et al., 2013), suggesting a possible compensatory mechanism (Konrad et al., 2002, 2006; Schoenfeld et al., 2005; Han and Ma, 2006; Lulé et al., 2007; Douaud et al., 2011). The correlation analysis between antisaccade preparatory activation and antisaccade reaction time showed significant negative correlations in the FP, DLPFC, insula, STR, SEF, and FEF, suggesting that greater preparatory activity in these ROIs corresponded to faster reaction times (Braun et al., 1992; Everling and Munoz, 2000; Connolly et al., 2005; Hakvoort Schwerdtfeger et al., 2012). Interestingly, although the insula has not traditionally been related to the saccade network, brain imaging studies have shown that it is constantly active during antisaccade tasks (Brown et al., 2006; Raemaekers et al., 2007), possibly because of its involvement with saliency processing (Menon and Uddin, 2010). In relation to the heightened activity, our results in various ROIs of the saccade network contrast with previous studies in other patient populations, such as Parkinson's disease and attention deficit hyperactivity disorder, which showed reduced preparatory activity in critical areas of the network, including SEF, FEF, PEF, STR, and DLPFC (Rieger et al., 2008; Cameron et al., 2012; Hakvoort Schwerdtfeger et al., 2012). This strongly suggests that ALS pathology has a main effect on antisaccades at the preparatory stage. Regarding the execution activity, the interaction analysis results showed that the core of the antisaccade network was similar for both groups. This is interesting because previous functional imaging reports have suggested changes in cortical activation boundaries (Kew et al., 1993). Although our experiment did not directly address this issue, the activity changes that we found point to a compensatory activation instead. However, it remains to be determined whether this activation increase is a byproduct of a decrease in interneuron inhibitory activity (Turner and Kiernan, 2012).

\section{Direction error activity}

In contrast to a block design, event-related studies allow for BOLD response analyses on a trial-by-trial basis. Exploiting this, we analyzed the BOLD signal from antisaccade trials where ALS patients made directional errors. We found a significant reduction in DLPFC preparatory activity during erroneous antisaccades, in contrast to higher than normal activity levels during correct antisaccades (discussed above), which supports our hypothesis that faulty antisaccade implementation in ALS is related to DLPFC dysfunction. Frontal lobe functional changes have been reported mainly on tasks related to language (Abrahams et al., 1996, 2004) and hand movement tasks (Kew et al., 1993; Konrad et al., 2002; Schoenfeld et al., 2005; Stanton et al., 2007; Mohammadi et al., 2011). The majority of those studies tested simple motor tasks; however, in one study ALS patients were instructed to make joystick movements in freely selected random sequences that are self-initiated responses that require some planning (Stanton et al., 2007). Although ALS patients showed increased activity centered in the primary sensorimotor cortex, they also showed reduced DLPFC activity (Stanton et al., 2007). These findings are similar to our results in that we found increased activity in a number of areas of the saccade network but reduced activity in the DLPFC when a subject made antisaccade errors. However, our experimental design allowed us to clearly distinguish the processes that were associated with these changes. Our analyses of the areas that showed activity increases during erroneous antisaccade trials showed that this heightened activity correlated with a smaller number of errors, reaching statistical significance in SEF and FEF. In contrast, the reduced DLPFC activation was specifically related to a faulty implementation of the task set.

In conclusion, our findings show that, in ALS patients, an abnormal DLPFC activation specifically during the establishment of the task set, is related to a deficit in the inhibition of automatic responses, a crucial process within the executive system. These results provide a direct link between a particular impairment of cognitive process and a functional deficit in the prefrontal cortex in ALS. Our results also show that ALS patients' heightened functional activity found in specific areas of the sac- 
cade network correlate with better responses, which fits with the concept of functional compensatory plasticity subsequent to the ALS neurological impairment. Further research should explore the mechanisms resulting in this compensatory plasticity and whether it could be exploited for therapeutic purposes.

\section{References}

Abrahams S, Goldstein LH, Kew JJ, Brooks DJ, Lloyd CM, Frith CD, Leigh PN (1996) Frontal lobe dysfunction in amyotrophic lateral sclerosis: a PET study. Brain 119:2105-2120. CrossRef Medline

Abrahams S, Leigh PN, Harvey A, Vythelingum GN, Grisé D, Goldstein LH (2000) Verbal fluency and executive dysfunction in amyotrophic lateral sclerosis (ALS). Neuropsychologia 38:734-747. CrossRef Medline

Abrahams S, Goldstein LH, Simmons A, Brammer M, Williams SC, Giampietro V, Leigh PN (2004) Word retrieval in amyotrophic lateral sclerosis: a functional magnetic resonance imaging study. Brain 127:1507-1517. CrossRef Medline

Ahn SW, Kim SH, Kim JE, Kim SM, Kim SH, Sung JJ, Lee KW, Hong YH (2011) Frontal assessment battery to evaluate frontal lobe dysfunction in ALS patients. Can J Neurol Sci 38:242-246. Medline

Alahyane N, Brien DC, Coe BC, Stroman PW, Munoz DP (2014) Developmental improvements in voluntary control of behavior: effect of preparation in the fronto-parietal network? Neuroimage 98:103-117. CrossRef Medline

Anderson EJ, Jones DK, O'Gorman RL, Leemans A, Catani M, Husain M (2012) Cortical network for gaze control in humans revealed using multimodal MRI. Cereb Cortex 22:765-775. CrossRef Medline

Bell AH, Meredith MA, Van Opstal AJ, Munoz DP (2006) Stimulus intensity modifies saccadic reaction time and visual response latency in the superior colliculus. Exp Brain Res 174:53-59. CrossRef Medline

Benton AL (1969) Development of a multilingual aphasia battery. J Neurol Sci 9:39-48. CrossRef Medline

Bjelland I, Dahl AA, Haug TT, Neckelmann D (2002) The validity of the Hospital Anxiety and Depression Scale: an updated literature review. J Psychosom Res 52:69-77. CrossRef Medline

Braun D, Weber H, Mergner T, Schulte-Mönting J (1992) Saccadic reaction times in patients with frontal and parietal lesions. Brain 115:1359-1386. CrossRef Medline

Brown MR, Goltz HC, Vilis T, Ford KA, Everling S (2006) Inhibition and generation of saccades: rapid event-related fMRI of prosaccades, antisaccades, and nogo trials. Neuroimage 33:644-659. CrossRef Medline

Brown MR, Vilis T, Everling S (2007) Frontoparietal activation with preparation for antisaccades. J Neurophysiol 98:1751-1762. CrossRef Medline

Burrell JR, Carpenter RH, Hodges JR, Kiernan MC (2013) Early saccades in amyotrophic lateral sclerosis. Amyotroph Lateral Scler Frontotemporal Degener 14:294-301. CrossRef Medline

Cameron IG, Coe BC, Watanabe M, Stroman PW, Munoz DP (2009) Role of the basal ganglia in switching a planned response. Eur J Neurosci 29: 2413-2425. CrossRef Medline

Cameron IG, Pari G, Alahyane N, Brien DC, Coe BC, Stroman PW, Munoz DP (2012) Impaired executive function signals in motor brain regions in Parkinson's disease. Neuroimage 60:1156-1170. CrossRef Medline

Cedarbaum JM, Stambler N, Malta E, Fuller C, Hilt D, Thurmond B, Nakanishi A (1999) The ALSFRS-R: a revised ALS functional rating scale that incorporates assessments of respiratory function. BDNF ALS Study Group (Phase III). J Neurol Sci 169:13-21. CrossRef Medline

Connolly JD, Goodale MA, Menon RS, Munoz DP (2002) Human fMRI evidence for the neural correlates of preparatory set. Nat Neurosci 5:1345-1352. CrossRef Medline

Connolly JD, Goodale MA, Goltz HC, Munoz DP (2005) fMRI activation in the human frontal eye field is correlated with saccadic reaction time. J Neurophysiol 94:605-611. CrossRef Medline

Cosottini M, Pesaresi I, Piazza S, Diciotti S, Cecchi P, Fabbri S, Carlesi C, Mascalchi M, Siciliano G (2012) Structural and functional evaluation of cortical motor areas in Amyotrophic Lateral Sclerosis. Exp Neurol 234: 169-180. CrossRef Medline

Curtis CE, D'Esposito M (2003) Success and failure suppressing reflexive behavior. J Cogn Neurosci 15:409-418. CrossRef Medline

Dale AM (1999) Optimal experimental design for event-related fMRI. Hum Brain Mapp 8:109-114. CrossRef Medline

DeSouza JF, Menon RS, Everling S (2003) Preparatory set associated with pro-saccades and anti-saccades in humans investigated with event-related FMRI. J Neurophysiol 89:1016-1023. CrossRef Medline
Donaghy C, Pinnock R, Abrahams S, Cardwell C, Hardiman O, Patterson V, McGivern RC, Gibson JM (2010) Slow saccades in bulbar-onset motor neurone disease. J Neurol 257:1134-1140. CrossRef Medline

Dorris MC, Munoz DP (1998) Saccadic probability influences motor preparation signals and time to saccadic initiation. J Neurosci 18:7015-7026. Medline

Dorris MC, Paré M, Munoz DP (1997) Neuronal activity in monkey superior colliculus related to the initiation of saccadic eye movements. J Neurosci 17:8566-8579. Medline

Douaud G, Filippini N, Knight S, Talbot K, Turner MR (2011) Integration of structural and functional magnetic resonance imaging in amyotrophic lateral sclerosis. Brain 134:3470-3479. CrossRef Medline

Esteban A, De Andrés C, Giménez-Roldan S (1978) Abnormalities of Bell's phenomenon in amyotrophic lateral sclerosis: a clinical and electrophysiological evaluation. J Neurol Neurosurg Psychiatry 41:690-698. CrossRef Medline

Evdokimidis I, Constantinidis TS, Gourtzelidis P, Smyrnis N, Zalonis I, Zis PV, Andreadou E, Papageorgiou C (2002) Frontal lobe dysfunction in amyotrophic lateral sclerosis. J Neurol Sci 195:25-33. CrossRef Medline

Everling S, Munoz DP (2000) Neuronal correlates for preparatory set associated with pro-saccades and anti-saccades in the primate frontal eye field. J Neurosci 20:387-400. Medline

Everling S, Dorris MC, Munoz DP (1998) Reflex suppression in the antisaccade task is dependent on prestimulus neural processes. J Neurophysiol 80:1584-1589. Medline

Everling S, Dorris MC, Klein RM, Munoz DP (1999) Role of primate superior colliculus in preparation and execution of anti-saccades and prosaccades. J Neurosci 19:2740-2754. Medline

Fischer B, Weber H (1997) Effects of stimulus conditions on the performance of antisaccades in man. Exp Brain Res 116:191-200. CrossRef Medline

Fischer B, Weber H, Biscaldi M, Aiple F, Otto P, Stuhr V (1993) Separate populations of visually guided saccades in humans: reaction times and amplitudes. Exp Brain Res 92:528-541. Medline

Flaherty-Craig C, Eslinger P, Stephens B, Simmons Z (2006) A rapid screening battery to identify frontal dysfunction in patients with ALS. Neurology 67:2070-2072. CrossRef Medline

Folstein MF, Robins LN, Helzer JE (1983) The Mini-Mental State Examination. Arch Gen Psychiatry 40:812. CrossRef Medline

Ford KA, Everling S (2009) Neural activity in primate caudate nucleus associated with prosaccade and antisaccades. J Neurophysiol 102:2334-2341. CrossRef Medline

Ford KA, Goltz HC, Brown MR, Everling S (2005) Neural processes associated with antisaccade task performance investigated with event-related FMRI. J Neurophysiol 94:429-440. CrossRef Medline

Forman SD, Cohen JD, Fitzgerald M, Eddy WF, Mintun MA, Noll DC (1995) Improved assessment of significant activation in functional magnetic resonance imaging (fMRI): use of a cluster-size threshold. Magn Res Med 33:636-647. CrossRef Medline

Gallassi R, Montagna P, Ciardulli C, Lorusso S, Mussuto V, Stracciari A (1985) Cognitive impairment in motor neuron disease. Acta Neurol Scand 71:480-484. CrossRef Medline

Guitton D, Buchtel HA, Douglas RM (1985) Frontal lobe lesions in man cause difficulties in suppressing reflexive glances and in generating goaldirected saccades. Exp Brain Res 58:455-472. Medline

Hakvoort Schwerdtfeger RM, Alahyane N, Brien DC, Coe BC, Stroman PW, Munoz DP (2012) Preparatory neural networks are impaired in adults with attention-deficit/hyperactivity disorder during the antisaccade task. Neuroimage Clin 2:63-78. CrossRef Medline

Hallett PE (1978) Primary and secondary saccades to goals defined by instructions. Vision Res 18:1279-1296. CrossRef Medline

Hallett PE, Adams BD (1980) The predictability of saccadic latency in a novel voluntary oculomotor task. Vision Res 20:329-339. CrossRef Medline

Han J, Ma L (2006) Functional magnetic resonance imaging study of the brain in patients with amyotrophic lateral sclerosis. Chin Med Sci J 21:228-233. Medline

Harvey DG, Torack RM, Rosenbaum HE (1979) Amyotrophic lateral sclerosis with ophthalmoplegia: a clinicopathologic study. Arch Neurol 36: 615-617. CrossRef Medline

Jacobs L, Bozian D, Heffner RR Jr, Barron SA (1981) An eye movement disorder in amyotrophic lateral sclerosis. Neurology 31:1282-1287. CrossRef Medline

Jamadar SD, Fielding J, Egan GF (2013) Quantitative meta-analysis of fMRI and PET studies reveals consistent activation in fronto-striatal-parietal 
regions and cerebellum during antisaccades and prosaccades. Front Psychol 4:749. CrossRef Medline

Kertesz A, Davidson W, Fox H (1997) Frontal behavioral inventory: diagnostic criteria for frontal lobe dementia. Can J Neurol Sci 24:29-36. Medline

Kew JJ, Leigh PN, Playford ED, Passingham RE, Goldstein LH, Frackowiak RS, Brooks DJ (1993) Cortical function in amyotrophic lateral sclerosis: a positron emission tomography study. Brain 116:655-680. CrossRef Medline

Kiernan MC, Vucic S, Cheah BC, Turner MR, Eisen A, Hardiman O, Burrell JR, Zoing MC (2011) Amyotrophic lateral sclerosis. Lancet 377:942955. CrossRef Medline

Konrad C, Henningsen H, Bremer J, Mock B, Deppe M, Buchinger C, Turski P, Knecht S, Brooks B (2002) Pattern of cortical reorganization in amyotrophic lateral sclerosis: a functional magnetic resonance imaging study. Exp Brain Res 143:51-56. CrossRef Medline

Konrad C, Jansen A, Henningsen H, Sommer J, Turski PA, Brooks BR, Knecht S (2006) Subcortical reorganization in amyotrophic lateral sclerosis. Exp Brain Res 172:361-369. CrossRef Medline

Kushner MJ, Parrish M, Burke A, Behrens M, Hays AP, Frame B, Rowland LP (1984) Nystagmus in motor neuron disease: clinicopathological study of two cases. Ann Neurol 16:71-77. CrossRef Medline

Leveille A, Kiernan J, Goodwin JA, Antel J (1982) Eye movements in amyotrophic lateral sclerosis. Arch Neurol 39:684-686. CrossRef Medline

Lulé D, Diekmann V, Kassubek J, Kurt A, Birbaumer N, Ludolph AC, Kraft E (2007) Cortical plasticity in amyotrophic lateral sclerosis: motor imagery and function. Neurorehabil Neural Repair 21:518-526. CrossRef Medline

Luna B, Thulborn KR, Strojwas MH, McCurtain BJ, Berman RA, Genovese CR, Sweeney JA (1998) Dorsal cortical regions subserving visually guided saccades in humans: an fMRI study. Cereb Cortex 8:40-47. CrossRef Medline

Marino RA, Levy R, Boehnke S, White BJ, Itti L, Munoz DP (2012) Linking visual response properties in the superior colliculus to saccade behavior. Eur J Neurosci 35:1738-1752. CrossRef Medline

Massman PJ, Sims J, Cooke N, Haverkamp LJ, Appel V, Appel SH (1996) Prevalence and correlates of neuropsychological deficits in amyotrophic lateral sclerosis. J Neurol Neurosurg Psychiatry 61:450-455. CrossRef Medline

Menon V, Uddin LQ (2010) Saliency, switching, attention and control: a network model of insula function. Brain Struct Funct 214:655-667. CrossRef Medline

Mohammadi B, Kollewe K, Samii A, Dengler R, Münte TF (2011) Functional neuroimaging at different disease stages reveals distinct phases of neuroplastic changes in amyotrophic lateral sclerosis. Hum Brain Mapp 32:750-758. CrossRef Medline

Moore SR, Gresham LS, Bromberg MB, Kasarkis EJ, Smith RA (1997) A self report measure of affective lability. J Neurol Neurosurg Psychiatry 63:8993. CrossRef Medline

Mueller J, Kiernan R, Langston J (2001) Manual for Cognistat (the Neurobehavioral Cognitive Status Examination). Fairfax, CA: Northern California Neurobehavioral Group.

Munoz DP, Corneil BD (1995) Evidence for interactions between target selection and visual fixation for saccade generation in humans. Exp Brain Res 103:168-173. Medline

Munoz DP, Everling S (2004) Look away: the anti-saccade task and the voluntary control of eye movement. Nat Rev Neurosci 5:218-228. CrossRef Medline

Munoz DP, Broughton JR, Goldring JE, Armstrong IT (1998) Age-related performance of human subjects on saccadic eye movement tasks. Exp Brain Res 121:391-400. CrossRef Medline

Murphy JM, Henry RG, Langmore S, Kramer JH, Miller BL, Lomen-Hoerth C (2007) Continuum of frontal lobe impairment in amyotrophic lateral sclerosis. Arch Neurol 64:530-534. CrossRef Medline

Nasreddine ZS, Phillips NA, Bédirian V, Charbonneau S, Whitehead V, Collin I, Cummings JL, Chertkow H (2005) The Montreal Cognitive Assessment, MoCA: a brief screening tool for mild cognitive impairment. J Am Geriatr Soc 53:695-699. CrossRef Medline

Ogawa S, Lee TM, Kay AR, Tank DW (1990) Brain magnetic resonance imaging with contrast dependent on blood oxygenation. Proc Natl Acad Sci U S A 87:9868-9872. CrossRef Medline

Ohki M, Kanayama R, Nakamura T, Okuyama T, Kimura Y, Koike Y (1994) Ocular abnormalities in amyotrophic lateral sclerosis. Acta Otolaryngol Suppl 511:138-142. Medline
Peltsch A, Hemraj A, Garcia A, Munoz DP (2011) Age-related trends in saccade characteristics among the elderly. Neurobiol Aging 32:669-679. CrossRef Medline

Phukan J, Pender NP, Hardiman O (2007) Cognitive impairment in amyotrophic lateral sclerosis. Lancet Neurol 6:994-1003. CrossRef Medline

Pierrot-Deseilligny C, Müri RM, Ploner CJ, Gaymard B, Demeret S, RivaudPechoux S (2003) Decisional role of the dorsolateral prefrontal cortex in ocular motor behaviour. Brain 126:1460-1473. CrossRef Medline

Poujois A, Schneider FC, Faillenot I, Camdessanché JP, Vandenberghe N, Thomas-Antérion C, Antoine JC (2013) Brain plasticity in the motor network is correlated with disease progression in amyotrophic lateral sclerosis. Hum Brain Mapp 34:2391-2401. CrossRef Medline

Raaphorst J, Beeldman E, De Visser M, De Haan RJ, Schmand B (2012) A systematic review of behavioural changes in motor neuron disease. Amyotroph Lateral Scler 13:493-501. CrossRef Medline

Raemaekers M, Vink M, Zandbelt B, van Wezel RJ, Kahn RS, Ramsey NF (2007) Test-retest reliability of fMRI activation during prosaccades and antisaccades. Neuroimage 36:532-542. CrossRef Medline

Rieger JW, Kim A, Argyelan M, Farber M, Glazman S, Liebeskind M, Meyer T, Bodis-Wollner I (2008) Cortical functional anatomy of voluntary saccades in Parkinson disease. Clin EEG Neurosci 39:169-174. CrossRef Medline

Schoenfeld MA, Tempelmann C, Gaul C, Kühnel GR, Düzel E, Hopf JM, Feistner H, Zierz S, Heinze HJ, Vielhaber S (2005) Functional motor compensation in amyotrophic lateral sclerosis. J Neurol 252:944-952. CrossRef Medline

Sharma R, Hicks S, Berna CM, Kennard C, Talbot K, Turner MR (2011) Oculomotor dysfunction in amyotrophic lateral sclerosis: a comprehensive review. Arch Neurol 68:857-861. CrossRef Medline

Shaunak S, Orrell RW, O'Sullivan E, Hawken MB, Lane RJ, Henderson L, Kennard C (1995) Oculomotor function in amyotrophic lateral sclerosis: evidence for frontal impairment. Ann Neurol 38:38-44. CrossRef Medline

Smith T, Gildeh N, Holmes C (2007) The Montreal Cognitive Assessment: validity and utility in a memory clinic setting. Can J Psychiatr Rev 52:329 332. Medline

Stanton BR, Williams VC, Leigh PN, Williams SC, Blain CR, Jarosz JM, Simmons A (2007) Altered cortical activation during a motor task in ALS: evidence for involvement of central pathways. J Neurol 254:1260-1267. CrossRef Medline

Strong MJ, Grace GM, Orange JB, Leeper HA (1996) Cognition, language, and speech in amyotrophic lateral sclerosis: a review. J Clin Exp Neuropsychol 18:291-303. CrossRef Medline

Talairach J, Tournoux P (1988) Co-planar stereotaxic atlas of the human brain: 3-dimensional proportional system: an approach to cerebral imaging. Stuttgart: Georg Thieme.

Tombaugh TN, Kozak J, Rees L (1999) Normative data stratified by age and education for two measures of verbal fluency: FAS and animal naming. Arch Clin Neuropsychol 14:167-177. CrossRef Medline

Tsermentseli S, Leigh PN, Goldstein LH (2012) The anatomy of cognitive impairment in amyotrophic lateral sclerosis: more than frontal lobe dysfunction. Cortex 48:166-182. CrossRef Medline

Turner MR, Kiernan MC (2012) Does interneuronal dysfunction contribute to neurodegeneration in amyotrophic lateral sclerosis? Amyotroph Lateral Scler 13:245-250. CrossRef Medline

Watanabe M, Munoz DP (2010) Presetting basal ganglia for volitional actions. J Neurosci 30:10144-10157. CrossRef Medline

Watanabe M, Munoz DP (2011) Probing basal ganglia functions by saccade eye movements. Eur J Neurosci 33:2070-2090. CrossRef Medline

Watanabe M, Munoz DP (2013) Effects of caudate microstimulation on spontaneous and purposive saccades. J Neurophysiol 110:334-343. CrossRef Medline

World Medical Association (2013) World Medical Association Declaration of Helsinki: ethical principles for medical research involving human subjects. JAMA 310:2191-2194. CrossRef Medline

Ziemann U, Winter M, Reimers CD, Reimers K, Tergau F, Paulus W (1997) Impaired motor cortex inhibition in patients with amyotrophic lateral sclerosis: evidence from paired transcranial magnetic stimulation. Neurology 49:1292-1298. CrossRef Medline

Zigmond AS, Snaith RP (1983) The Hospital Anxiety and Depression Scale. Acta Psychiatr Scand 67:361-370. CrossRef Medline 